\title{
Managing Patients Undergoing Orthopedic Surgery to Improve Glycemic Outcomes
}

\author{
Ruben Diaz $^{1}$ (D) . Jenny DeJesus ${ }^{1}$ \\ Accepted: 25 October 2021 / Published online: 6 January 2022 \\ (c) The Author(s), under exclusive licence to Springer Science+Business Media, LLC, part of Springer Nature 2021
}

\begin{abstract}
Purpose of Review Persons with diabetes are more likely to require orthopedic surgery and are at an increased risk of developing postoperative complications. Recognizing the impact of diabetes on musculoskeletal health provides an opportunity to educate healthcare professionals in standardizing the perioperative approach of persons with diabetes.

Recent Findings Elevated hemoglobin A1C, fructosamine, and blood glucose levels have been associated with increased risk for complications in the orthopedic population. These risks can be mitigated by the early identification and optimization of these patients in the perioperative period. Intraoperative and postoperative glycemic management should support efforts to maintain glucose at safe levels while avoiding hyperglycemia and hypoglycemia.

Summary This paper considers factors surrounding diabetes care in the orthopedic surgical patient. Perioperative care discussed includes optimization, hospitalization to discharge, and special considerations such as steroids and diabetes wearable technology. Hospitals should consider these strategies towards enhancing the care of persons with diabetes requiring musculoskeletal care.
\end{abstract}

Keywords Diabetes mellitus $\cdot$ Orthopedic surgery $\cdot$ Hyperglycemia $\cdot$ Perioperative

\section{Introduction}

Diabetes is a prevalent condition with more than 34.2 million people in the United States (U.S.) affected and projected to increase [1]. An estimated 1 in 4 patients admitted to the hospital has known diabetes; furthermore, persons with diabetes (PWD) are more frequently hospitalized [2]. It is estimated that 10 to $20 \%$ of hospitalized orthopedic surgery patients have diabetes [3]. Hyperglycemia is common in this population during hospitalization. Corsino et al. estimated that 22 to $46 \%$ of the non-critically ill experience hyperglycemia with or without a diabetes diagnosis and Umpierrez et al. reported hyperglycemia in 32 to $38 \%$ of the inpatient population in community hospitals $[4,5]$. There is substantial evidence of the adverse effects of hyperglycemia in the hospitalized patient with a higher rate of surgical site

This article is part of the Topical Collection on Hospital Management of Diabetes

Ruben Diaz

diazr@hss.edu

1 Hospital for Special Surgery, New York, NY 10021, USA infection and increased risk of stroke, urinary tract infection, ileus, hemorrhage, transfusion, and mortality [6, 7].

PWD are at a higher risk and incidence of musculoskeletal conditions that require orthopedic attention [8,9]. Musculoskeletal symptoms are more prevalent, severe, often overlooked, and undertreated in comparison to other more well-known diabetes-associated conditions such as cardiovascular and renal complications [10]. It is theorized that orthopedic complications in PWD are an indirect result of underlying metabolic abnormalities affecting healing response, neurovascular changes, microvascular perfusion, macrovascular complications, and altered bone turnover [6]. The most common hospital-acquired infection is surgical site infection, disproportionately affecting patients with diabetes, particularly when blood glucose is in excess or with high variability [11].

\section{Preoperative Period}

The preoperative period presents an opportunity for the early identification of PWD and allows for preoperative optimization of the patient as a risk mitigation strategy. The elements 
Table 1 Preoperative evaluation of persons with diabetes

Type and duration of diabetes mellitus

Treatment regimen; pharmacology and wearable diabetes technology

Current glycemic management

Hypoglycemia frequency, awareness, events requiring assistance

Complications related to diabetes

Surgical procedure

of an initial history for PWD are listed in Table 1. Type 1 (T1D) and type 2 (T2D) diabetes mellitus are the most common types of diabetes identified, and the duration informs the length of time of glycemic exposure, which increases the risk of diabetes-associated complications. Persons with T1D produce little to no insulin and require insulin therapy. Blood glucose variability, hypoglycemia unawareness, and an increased risk of severe hypoglycemia and diabetic ketoacidosis (DKA) are common in T1D. Persons with T2D have insulin resistance and reduced insulin secretion. T2D may be managed with dietary and physical activity changes in addition to oral antihyperglycemic agents, non-insulin injectables, and insulin. Wearable diabetes technology to assist with diabetes management has increased in popularity and is discussed under special considerations later in this paper.

PWD should have a hemoglobin A1c (A1C) checked as part of their preoperative labs [8, 12, 13]. A1C has been the gold standard for assessing glycemic management over time in PWD; therefore, it is used to determine eligibility for elective orthopedic surgery [14, 15]. The A1C provides an indirect measure of the average blood glucose for the past 2 to 3 months $[14,16]$. A preoperative A1C target lacks consensus and is based on the association of A1C as a predictor for adverse outcomes in orthopedic surgery. The A1C cutoff for surgery varies widely from less than 7 to $9 \%$ [17-19]. An A1C goal of $<8 \%$ has been widely used for PWD undergoing elective surgery as an elevated $\mathrm{A} 1 \mathrm{C}$ is associated with an increased risk of surgical site infections [6, 20-22].

The correlation between typical A1C cutoff and outcomes following orthopedic surgery has been inconsistent, likely due to variations in study methodology [14, 23]. Tarabichi et al. observed an association between elevated A1C levels and an increased risk for periprosthetic joint infections (PJI) [24]. Moreover, they found that an A1C $>7.7 \%$ was more suggestive of this increased risk, supporting the preoperative A1C target of $<8 \%$ [24]. Additional measures such as fructosamine and perioperative glucose levels have demonstrated to be of importance in evaluating postoperative outcomes $[13,23]$.

While $\mathrm{A} 1 \mathrm{C}$ is the recommended marker for glycemic outcomes, some challenges exist with its use in preoperative glycemic optimization, due to its lagging effect [23, 25].
This may result in unnecessary delay of elective surgical procedures. As a result, the use of serum fructosamine and blood glucose levels as adjustive markers of preoperative glycemia has been explored. Serum fructosamine is an inexpensive test that measures the levels of glycated serum proteins [14, 23]. It reflects a shorter glycemic average of a 2- to 3-week period in contrast to the 2- to 3-month average measured by A1C [14]. Fructosamine levels have been found to be a useful predictor of adverse outcomes in the orthopedic surgical population. Since serum fructosamine

Table 2 Factors that falsely increase or decrease $\mathrm{A} 1 \mathrm{C}$

False low A1c
Hemolysis
Hemodialysis
Blood transfusion
Pregnancy
Rheumatoid arthritis
Aspirin, antiretrovirals
Vitamin B6 deficiency
Vitamin C and E
False high A1c
Iron deficiency anemia
Pernicious anemia
Hemoglobinopathies (i.e.,
thalassemia)
Kidney disease
Jaundice
Alcoholism
Uremia
Lead poisoning

Table 3 Factors that falsely increase or decrease serum fructosamine

Low serum fructosamine (decreased protein)
Malnutrition (lack of protein in diet)
Gut disease (protein-losing enteropathies)
Hyperthyroidism
Liver disease (i.e., cirrhosis)
Kidney disease (nephrotic syndrome)
Obesity
Pregnancy
Vitamin C (high levels of ascorbic acid)
High serum fructosamine (increased protein)
Increased antibody production (i.e., IgA, multiple myeloma)
Paraproteinemia (increased bilirubin)
Hypothyroidism
Iron deficiency anemia
Uremia
Dyslipidemia
Glucocorticoids
Chinese herb: Polygale Radix


responds quicker to treatment in comparison to $\mathrm{A} 1 \mathrm{C}$, it is a valuable marker for evaluation of short-term glycemic outcomes $[14,23]$. Several factors should be considered when evaluating $\mathrm{A} 1 \mathrm{C}$ and serum fructosamine results, as some patient-specific factors may impact on its accuracy (see Table 2, Table 3) [26-29].

Elevated perioperative average blood glucose levels have also been associated with poor surgical outcomes including higher 30-day mortality in the non-cardiac surgical population $[13,15]$. Van de Boom et al. found that an elevated A1C was not predictive of 30-day mortality after controlling for blood glucose, suggesting that perioperative glucose management may neutralize the effect of an elevated A1C on postoperative complications [15]. Thus, their results suggest that improving perioperative glucose outcomes may be an important risk mitigation strategy in persons with diabetes with an elevated A1C.

PWD are at increased risk of coronary artery disease, diabetic kidney disease, and diabetic peripheral neuropathy [30-33]. Given the strong association of diabetes and microvascular and macrovascular disease, in addition to standard preoperative testing, a renal panel and electrocardiogram should be included. This will assist in assessing the cardiac risk in response to the metabolic demands encountered around surgery and the impact of renal function on surgical and anesthetic management. This also allows for preoperative optimization of the patient as a risk mitigation strategy. Lower extremity peripheral vascular examination should include assessing for any skin compromise such as a wound or ulceration.

The nature and extent of a surgical procedure are factored into the individualized approaches to glycemic management perioperatively. A stereotypical stress response to surgery, increased glycemic monitoring, and possible use of an IV insulin infusion are more common in a major procedure with anesthesia time of $>1 \mathrm{~h}$. In minor surgery, there is no specific therapy and a preoperative dose of short-acting insulin in cases of hyperglycemia $>200 \mathrm{mg} / \mathrm{dl}$ may be all that is required [34]. Anticipated anesthesia and any steroid administration will determine the degree of impact on glycemic control and may guide the preoperative discussion. Epidural anesthesia or a combination of general-epidural anesthesia would have a less significant impact on blood glucose outcomes than general anesthesia [35].

\section{Preoperative Optimization}

Preoperative glycemic optimization is advised prior to elective procedures given the association between orthopedic postoperative complications and glycemia [36]. Elective cases should be referred to their diabetes care team to assist with optimizing glycemic outcomes in preparation for surgery [37]. The minimum anticipated optimization period is often 4 to 6 weeks and may be as long as 2 to 3 months.

Glycemic optimization in anticipation of a surgical procedure may include a variety of interventions, including dietary counseling and adjustments of medication therapy. Nutrition therapy is a crucial component of diabetes management and is perhaps the most challenging for most PWD [38]. According to the American Diabetes Association recommendations, clinicians should provide patients with practical tools they can use to develop healthy eating patterns with the following key components: (1) increasing intake of non-starchy vegetables, (2) choosing whole foods over processed whenever possible, and (3) minimizing added sugars and refined grains, taking any medical dietary restrictions into consideration. Intake of lean proteins is also important with individualized meal planning [38].

Adjustments to antihyperglycemic medication therapy will be based on diabetes type, co-morbid conditions, current regimen, and time span available for optimization. In patients with T1D, optimization of insulin therapy would be the primary intervention. For those with T2D, a stepwise approach for intensification of glucose-lowering medications is recommended [39]. An approach of shared decision-making when considering therapeutic agents enhances the likelihood of the PWD adopting the intervention.

Motivational interviewing is useful in supporting selfmanagement during optimization. Diabetes survival skills, daily management issues, and problem solving should be included as part of the general education and continued perioperatively. Close engagement with the patient to review blood glucose readings, titrate medications, and capture any barriers or challenges encountered by the patient is needed during the optimization process. Clear mutually agreed goals set with the PWD including glycemic targets facilitates collaboration. There are no specified preoperative glucose targets, but the recommended American Diabetes Association (ADA) outpatient glucose targets can be used; pre-prandial $80-130 \mathrm{mg} / \mathrm{dl},<180 \mathrm{mg} / \mathrm{dl} 1-2 \mathrm{~h}$ postprandial [40]. Published recommended safe ranges vary from 100 to $200 \mathrm{mg} /$ dl $[11,18]$. Once glycemic targets are achieved, surgery may be scheduled.

\section{Preoperative Instructions}

PWD should be provided with clear, written instructions on adjustments to their medication regimen for the perioperative period [13]. Fasting duration, time of surgery, half-life of agent(s), and risk of hypoglycemia are all considered when deciding when to withhold anti-diabetic medications in the perioperative period [41]. If applicable, blood glucose self-monitoring should be performed prior to departure to 
the hospital and with availability of hypoglycemia intervention including when nil by mouth (NPO).

In most cases, persons with T2D can take their usual oral antihyperglycemics the day prior to the procedure and hold them on the day of the procedure [41]. Those on insulin therapy will need adjustments to their insulin regimen to prevent hypoglycemia during prolonged fasting. Therapy adjustments should be individualized based on insulin regimen and patient factors. An observational study conducted by Demma et al. found that $75 \%$ of the usual basal dose resulted in target blood glucose of $100-180 \mathrm{mg} / \mathrm{dl}$, and less hypoglycemia on the day of the procedure in persons with T2D [42]. For those that administer their basal insulin in the morning, they may reduce the dose to $50 \%$ of the usual basal dose [13]. Patients on mixed insulin should be advised to take the usual evening dose the day before and hold the morning dose the day of the procedure to avoid hypoglycemia [13]. Given the complexity of diabetes management in the fasting state, patients with diabetes should be prioritized to early surgical scheduling times.

An effort should be made to prepare the PWD for what to expect during their hospital stay including capillary blood glucose monitoring in the hospital, insulin administration regardless of home therapeutics, and expected blood glucose lability (Table 4). This is intended to promote satisfaction with care and help alleviate anxiety. PWD should be encouraged to participate in their diabetes care and management during the hospital admission as much as possible in collaboration with their care team. The management of diabetes regimens before surgery should follow standardized preoperative institutional guidelines for diabetes medication dose reduction or timely temporary discontinuation of therapy for patient safety, while attempting to maintain adequate glycemic outcomes. If applicable, frequent blood glucose selfmonitoring when NPO with appropriate hypoglycemia and hyperglycemia management instructions should be provided.

\section{Hospital Admission}

To reduce the effects of metabolic stress such as insulin resistance due to prolonged fasting and surgery, preoperative carbohydrate treatment has been used as an approach to

Table 4 Preoperative instruction for PWD

Adjustments to diabetes medications

Time of last meal

Glucose monitoring in anticipation of procedure

Management of hypo/hyperglycemia while NPO

If on an insulin pump advise on infusion set change and to bring extra supplies

Educate on inpatient diabetes management improve postoperative outcomes and reduce length of stay (LOS). The Enhanced Recovery After Surgery (ERAS) surgical care pathway is a multifaceted approach to improve postoperative outcomes and LOS, which includes carbohydrate loading the morning of surgery [43]. Preoperative carbohydrate treatment to reduce the stress response to surgery has not been well studied in persons with diabetes and is recommended with caution in optimized patients due to the risk of compromising blood glucose control [44]. Further studies are needed in persons with diabetes before it is implemented for this group, particularly in orthopedic surgery.

The admission assessment includes a review of the PWD home medications including the time and dose of the last diabetes medication taken. This information should be recorded in the electronic health record (EHR). The blood glucose should be checked with a hospital-owned device to establish baseline blood glucose during the admission process. A blood glucose of $<70 \mathrm{mg} / \mathrm{dl}$ is defined as hypoglycemia that requires taking action and should be treated immediately preoperatively. Intravenous (IV) dextrose infusion is the preferred treatment given their NPO status. If the glucose is $>200 \mathrm{mg} / \mathrm{dl}$ at the time of admission, the care team should collaborate with anesthesia and consider treating the hyperglycemia with rapid-acting insulin as a glucose $<200 \mathrm{mg} / \mathrm{dl}$ is recommended in the perioperative period [14].

\section{Intraoperative Period}

Numerous factors influence intraoperative glycemic fluctuations and require consistent monitoring. Elevated glucose levels occur with infection, trauma, hypothermia, general anesthesia, drugs such as steroids, fluids, and nutritional support [18]. Epidural anesthesia tends to have a negligible effect on blood glucose levels [34]. Insulin and fluid administration during surgery aims to maintain glycemic outcomes and hemodynamic stability. During surgery, blood glucose should be monitored every 1 to $2 \mathrm{~h}$ after $>1 \mathrm{~h}$ postinduction of anesthesia. Avoidance of hypoglycemia is a priority in the sedated patient. A degree of hyperglycemia is accepted with practice guidelines recommending insulin intervention at ranges from 150 to $200 \mathrm{mg} / \mathrm{dl}$ [20]. Intraoperative blood glucose targets recommended by several organizations range from 140 to $200 \mathrm{mg} / \mathrm{dl}$ [20].

If subcutaneous insulin administration is the route of choice for the management of intraoperative hyperglycemia, it should be administered at least $2 \mathrm{~h}$ apart to prevent insulin stacking [20]. IV insulin infusion has advantages over subcutaneous insulin delivery due to unpredictable absorption if there are changes in tissue perfusion. IV insulin delivery is the route of choice for critically ill or complex procedures, duration of surgery longer than $4 \mathrm{~h}$, to replace a discontinued continuous subcutaneous insulin infusion (insulin pump), 
or in cases of severe or persistently elevated blood glucose despite conservative measures. A paper-based or computerized IV insulin infusion protocol based on rate of change is recommended [45, 46].

IV fluid management often consists of either normal saline or lactated Ringer's (Hartmann) solutions. Recent data does not support the suggested hyperglycemic effects of lactated Ringer's in persons with diabetes undergoing surgery $[47,48]$. Initiation of dextrose containing IV fluid is not required to prevent hypoglycemia in elective surgery and can lead to transient hyperglycemia [49]. In cases of severe hyperglycemia with metabolic acidosis, large volumes of normal saline infusion can worsen metabolic acidosis by increasing chloride and decreasing bicarbonate, whereas the sodium lactate in lactated ringers serves as a buffer [50].

\section{Postoperative Period}

A transition to the postoperative phase of care should prompt a reassessment of the patient and addressing ongoing glycemic needs. Immediate blood glucose assessment is necessary due to the risk of sedation and any intraoperative beta blocker administration masking symptoms of hypoglycemia. Postoperative management depends on the persons condition, nutritional status, and glycemic control. Postoperative blood glucose targets outside of the intensive care setting range from 140 to $180 \mathrm{mg} / \mathrm{dl}$, and lower range of 110 to 140 $\mathrm{mg} / \mathrm{dl}$ for select patients [12, 51, 52]. Hyperglycemia in the hospitalized patient is a blood glucose $>140 \mathrm{mg} / \mathrm{dl}$, with a threshold of $\geq 180 \mathrm{mg} / \mathrm{dl}$ persistently as a target for initiating insulin therapy [12]. Continuous IV insulin infusion initiation may also be considered with uncontrolled hyperglycemia in the non-critically ill with a blood glucose of $>300$ to $350 \mathrm{mg} / \mathrm{dl}$, or persistently $>200 \mathrm{mg} / \mathrm{dl}$ for $>12 \mathrm{~h}$, despite subcutaneous insulin administration.

Standardized clinical guidelines for hospital management of a PWD and any associated dysglycemia should be implemented and include best practices as a coordinated and collaborative effort to achieve desired outcomes. Immediate priorities include appropriate fluid administration, electrolyte balance, and blood glucose management. Insulin is the pharmacologic agent of choice to manage blood glucose in hospitalized patients requiring glycemic management due to its quick onset and ease of adjustment based on dynamic individual needs [53]. Structured insulin order sets should be implemented to increase efficiency and decrease dosing errors. In 2009, the national recommendations for inpatient glycemic management included the more physiologic method of basal-bolus insulin therapy instead of "sliding scale" short or rapid-acting insulin as sole therapy [54].

Antiglycemic oral agents and non-insulin injectables are not currently recommended postoperatively until close to the time of discharge due to the lack of safety and efficacy in hospitals [12]. Most recently, some studies have suggested that glucagon-like peptide-1 (GLP-1) receptor agonists and dipeptidyl peptidase-4 (DPP-4) inhibitors are potentially beneficial in hospitalized patients with moderate hyperglycemia [55].

Hospital diabetes management teams vary by institutions based on needs and resources. The increase in the diabetes population seeking care, advancement in diabetes therapies and technology, potential for improved outcomes, and cost savings are a few of the factors that support implementation of a diabetes management program [53]. Involvement of a diabetes service in select patients from the preoperative or admission phase to discharge enhances the entire perioperative experience and associated outcomes such as length of stay, readmission, and mortality [56].

\section{Discharge}

Transitioning from hospital to home requires planning and starts on admission. There is no single strategy and requires multidisciplinary involvement. The Joint Commission and the Agency for Healthcare Research and Quality recommend diabetes education and assessment, medication reconciliation and appropriate prescribing, and structured discharge communication for a safe and effective discharge [12, 57]. The most recent $\mathrm{A} 1 \mathrm{C}$, in addition to patient presentation and inpatient glycemic outcomes, provides guidance for the post-discharge regimen [58]. An A1C discharge algorithm to promote glycemic management after discharge has been shown to be beneficial [59]. Additional strategies for successful discharge planning include a discharge follow-up call within 2-3 days from discharge, home visits with diabetes support, and a transitional care clinic in addition to scheduling a timely outpatient provider follow-up visit $[12,18]$.

\section{Special Considerations}

The prophylactic use of perioperative glucocorticoids for nausea and pain in patients undergoing orthopedic surgery is common [12]. Glucocorticoid administration leads to transient hyperglycemia, more pronounced in the first $24 \mathrm{~h}$ after surgery, due to an increase in insulin resistance [60]. Increases in glucose levels of up to $68 \%$ from baseline have been observed [61]. Patients with and without diabetes with elevated perioperative glucose are at greater risk of developing hyperglycemia after steroid administration. Careful consideration should be given in patient selection and dosing of intraoperative steroids to decrease the risk of severe 
hyperglycemia. Despite the association with hyperglycemia, steroid therapy in this population has been found to decrease length of stay, pain, and narcotic use [62].

Patients who receive glucocorticoids should be monitored closely for elevations in blood glucose in the postoperative phase of care. Elevations in glucose should be treated promptly with subcutaneous insulin administration [51]. In cases of severe persistent hyperglycemia, IV continuous insulin infusion can be considered. Tapering and discontinuation of steroid should prompt prescribers to adjust insulin therapy to decrease the risk of hypoglycemia [56].

\section{Diabetes Technology}

Diabetes technology is often utilized in T1D and increasingly in T2D, including insulin pump and continuous glucose monitoring (CGM) systems. It is estimated that approximately $60 \%$ of persons with T1D wear an insulin pump [63]. The number of persons using insulin pumps and CGMs is expected to increase as features such as automated insulin delivery become more available. The use of insulin pumps or CGM should be identified during the pre-admission visit and hospital staff should become familiar with caring for PWD wearing these devices.

The use of an insulin pump in the hospital should be supported by an endocrine consult whenever possible. Insulin pumps may be safely used in the hospital setting with appropriate patient selection, availability of a diabetes care team, and a standardized hospital policy. Several studies have shown no difference in hospital glucose averages between PWD continued on an insulin pump and those transitioned to subcutaneous insulin injections during the hospital stay [63]. Considerations to discontinue the insulin pump include patient preference and when the patient is unable to self-manage with their insulin pump. Removal or discontinuation of the insulin pump requires insulin replacement therapy with an IV insulin infusion or basal and bolus subcutaneous insulins to prevent hyperglycemia escalation and possibly ketosis [63].

Insulin pump therapy may be continued during the intraoperative period with some consideration. Generally, it is safe to continue insulin pump therapy if the length of the surgery is up to 2 to $3 \mathrm{~h}$ [63]. Precautionary considerations for intraoperative diabetes technology include electrocautery, electromagnetic field exposure, and flammable anesthetic agents [64]. Insulin pumps and metal infusion sets should be removed for MRIs and should be covered with a lead apron during X-rays and computerized tomography [63].

Continuous glucose monitors (CGMs) are worn by many persons with diabetes, especially those on multiple-dose insulin therapy (MDI) and insulin pumps. Real-time or intermittently scanned CGMs measure glucose in the interstitial fluid. CGMs have not been approved to replace hospital blood glucose monitors since results may not correlate with rapid changes in blood glucose, and often lag actual blood glucose results. During the COVID-19 pandemic, CGMs received temporary enforcement discretion from the U.S. Food and Drug Administration (FDA) and were tried in some hospitals. In the future, CGMs may gain FDA approval for select acute care populations.

\section{Conclusion}

Hyperglycemia and the sequela of infection are a cause for concern and constitutes a significant challenge in the orthopedic surgical patient. The evidence is clear that the risk of complications, including infection and increased mortality, is greater in patients with hyperglycemia compared to the general population. Instituting a process of care of PWD undergoing orthopedic surgery from the preoperative period through discharge home has the potential to improve outcomes.

Author Contribution All authors contributed to the literature search and manuscript. The first draft of the manuscript was written by Ruben Diaz and all authors commented on previous versions of the manuscript. All authors read and approved the final manuscript.

Availability of Data and Material Not applicable

Code Availability Not applicable

\section{Declarations}

Conflict of Interest The authors declare no competing interests.

\section{References}

1. Centers for Disease Control and Prevention (CDC). National Diabetes Statistic Report. 2020. Retrieved from https://www.cdc.gov/ diabetes/data/statistics-report/index.html. Accessed 11 Oct 2021.

2. Farrokhi F, Smiley D, Umpierrez GE. Glycemic control in nondiabetic critically ill patients. Best Pract Res Clin Endocrinol Metab. 2011;25(5):813-24. https://doi.org/10.1016/j.beem.2011. 05.004 .

3. Schroeder JE, Liebergall M, Raz I, Egleston R, Sussan GB, Peyser A, Eldor R. Benefits of a simple glycaemic protocol in an orthopaedic surgery ward: a randomized prospective study. Diabetes Metab Res Rev. 2012;28:71-5.

4. Corsino L, Dhatariya K, Umpierrez G. Management of diabetes and hyperglycemia in hospitalized patients. 2014. Endotext Available from: https://www.ncbi.nlm.nih.gov/books/NBK279093/. Accessed 30 June 2021.

5. Umpierrez GE, Hellman R, Korytkowski MT, Kosiborod M, Maynard GA, Montori VM, ..., Endocrine Society. Management of hyperglycemia in hospitalized patients in non-critical care setting: 
an endocrine society clinical practice guideline. J Clin Endocrinol Metab. 2012;97(1):16-38.https://doi.org/10.1210/jc.2011-2098

6. Gehling DJ, Lecka-Czernik B, Ebraheim NA. Orthopedic complications in diabetes. Bone. 2016;82:79-92.

7. Marchant MH Jr, Viens NA, Cook C, Vail TP, Bolognesi MP. The impact of glycemic control and diabetes mellitus on perioperative outcomes after total joint arthroplasty. J Bone Joint Surg Am. 2009;91(7):1621-9. https://doi.org/10.2106/JBJS.H.00116.

8. Rizvi AA, Chillag SA, Chillag KJ. Perioperative management of diabetes and hyperglycemia in patients undergoing orthopaedic surgery. J Am Acad Orthop Surg. 2010;18(7):426-35.

9. Pai LW, Hung CT, Li SF, Chen LL, Chung Y, Liu HL. Musculoskeletal pain in people with and without type 2 diabetes in Taiwan: a population-based, retrospective cohort study. BMC Musculoskelet Disord. 2015;16(1):364.

10. Yang YL, Chee W, Im EO. Type 2 diabetes and musculoskeletal symptoms among midlife women. Diabetes Educ. 2019;45(5):520-8. https://doi.org/10.1177/0145721719872558.

11. Akiboye F, Rayman G. Management of hyperglycemia and diabetes in orthopedic surgery. Curr Diab Rep. 2017;17(2):13-0170839-6. https://doi.org/10.1007/s11892-017-0839-6.

12. American Diabetes Association (ADA). Diabetes care in the hospital: standards of medical care in diabetes-2021. Diabetes Care. 2021;44(1):S211-220. https://doi.org/10.2337/dc21-S015.

13. Simha V, Shah P. Perioperative glucose control in patients with diabetes undergoing elective surgery. J Am Med Assoc. 2019;321(4):399-400. https://doi.org/10.1001/jama.2018.20922.

14. Govindan N. Glycemic markers in operative orthopaedics: is fructosamine better than HbA1c. Orthop Musc Syst Curr Res. 2020;9(279). https://doi.org/10.35248/2161-0533.2020.9.279.

15. van den Boom W, Schroeder RA, Manning MW, Setji TL, Fiestan GO, Dunson DB. Effect of A1C and glucose on postoperative mortality in noncardiac and cardiac surgeries. Diabetes Care. 2018;41(4):782-8. https://doi.org/10.2337/dc17-2232.

16. Mahoney D. Beware of the possibility of unreliability of A1c. J Nurse Pract. 2020;16:420-4.

17. Dhatariya K, Levy N, Kilvert A, Watson B, Cousins D, Flanagan D, Hilton L, Jairam C, Leyden K, Lipp A, Lobo D, SinclairHammersley M, Rayman G, Joint British Diabetes Societies. NHS Diabetes guideline for the perioperative management of the adult patient with diabetes. Diabet Med. 2012;29(4):420-33. https:// doi.org/10.1111/j.1464-5491.2012.03582.x.

18. Gianchandani R, Dubois E, Alexanian S, Rushakoff R. Preoperative, intraoperative, and postoperative glucose management. In: Draznin B, editor. managing diabetes and hyperglycemia in the hospital setting. Arlington County: American Diabetes Association; 2016. p. 129-44.

19. Yang L, Sun Y, Li G, Liu J. Is hemoglobin A1c and perioperative hyperglycemia predictive of periprosthetic joint infection following total joint arthroplasty?: A systematic review and meta-analysis. Medicine. 2017;96(51):e8805. https://doi.org/10.1097/MD. 0000000000008805

20. Duggan EW, Carlson K, Umpierrez GE. Perioperative hyperglycemia management: an update. Anesthesiology. 2017;126(3):547-60.

21. Stryker LS, Abdel MP, Morrey ME, Morrow MM, Kor DJ, Morrey $\mathrm{BF}$. Elevated postoperative blood glucose and preoperative hemoglobin $\mathrm{A} 1 \mathrm{C}$ are associated with increased wound complications following total joint arthroplasty. J Bone Joint Surg Am. 2013;95(9):808-S2. https://doi.org/10.2106/JBJS.L.00494.

22. Wukich DK, Crim BE, Frykberg RG, Rosario BL. Neuropathy and poorly controlled diabetes increase the rate of surgical site infection after foot and ankle surgery. J Bone Joint Surg Am. 2014;96(10):832-9. https://doi.org/10.2106/JBJS.L.01302.

23. Shohat N, Tarabichi M, Tischler EH, Jabbour S, Parvizi J. Serum fructosamine: a simple and inexpensive test for assessing preoperative glycemic control. J Bone Joint Surg Am. 2017;99(22):1900-7. https://doi.org/10.2106/JBJS.17.00075.

24. Tarabichi M, Shohat N, Kheir MM, Adelani M, Brigati D, Kerans SM, Pankajkumar P, Clohisy JC, Higuera CA, Levinem BR, Schwarzkopf R, Parvizi J, Jiranek WA. Determining the threshold for $\mathrm{HbAlc}$ as a predictor for adverse outcomes after total joint arthroplasty: a multicenter retrospective study. J Arthroplasty. 2017;32:S253-267.

25. Wright JG. A cheap, simple test that predicts complications: what's not to like?: Commentary on an article by Noam Shohat, MD et al.: "Serum fructosamine: a simple and inexpensive test for assessing preoperative glycemic control." J Bone Joint Surg Am. 2017;99(22):e122. https://doi.org/10.2106/JBJS.17.00826.

26. Danese E, Montagnana M, Nouvenne A, Lippi G. Advances and pitfalls of fructosamine and glycated albumin in the diabetes of and treatment of diabetes. J Diabetes Sci Technol. 2015;9(2):169-72.

27. Gounden V, Ngu M, Anastasopoulou C, et al. Fructosamine. In: StatPearls Treasure Island: StatPearls Publishing. 2020. Available from: https://www.ncbi.nlm.nih.gov/books/NBK470185/. Accessed 10 Aug 2021.

28. Mohsin ZA, Paul A, Devendra S. Pitfalls of using $\mathrm{HbA}_{1 \mathrm{c}}$ in the diagnosis and monitoring of diabetes. Lond $\mathrm{J}$ Prim Care. 2015;7(4):66-9. https://doi.org/10.1080/17571472.2015.11493 437.

29. Radin MS. Pitfalls in hemoglobin A1c measurement: when results may be misleading. J Gen Intern Med. 2014;29(2):388 94. https://doi.org/10.1007/s11606-013-2595-x.

30. American Diabetes Association (ADA). Cardiovascular disease and risk management: standards of medical care in diabetes-2021. Diabetes Care. 2021;44(1):S125-150. https://doi.org/ 10.2337/dc21-S010.

31. Centers for Disease Control and Prevention (CDC). National diabetes statistics report. 2020. Retrieved from https://www. cdc.gov/diabetes/pdfs/data/statistics/national-diabetes-statisticsreport.pdf. Accessed 25 July 2021.

32. Hicks CW, Selvin E. Epidemiology of peripheral neuropathy and lower extremity disease in diabetes. Curr DiabRep. 2019;19(10):86. https://doi.org/10.1007/s11892-019-1212-8.

33. Leon BM, Maddox TM. Diabetes and cardiovascular disease: epidemiology, biological mechanisms, treatment recommendations and future research. World J Diabetes. 2015;6(13):1246-58. https://doi.org/10.4239/wjd.v6.i13.1246.

34. Sudhakaran S, Surani SR. Guidelines for perioperative management of the diabetic patient. Surg Res Pract. 2015;2015:284063. https://doi.org/10.1155/2015/284063.

35. Li X, Wang J, Chen K, Li Y, Wang H, Mu Y, Chen Y. Effect of different types of anesthesia on intraoperative blood glucose of diabetic patients: a PRISMA-compliant systematic review and meta-analysis. Medicine. 2017;96(13):e6451. https://doi.org/10. 1097/MD.0000000000006451.

36. Levy N, Dhatariya K. Pre-operative optimisation of the surgical patient with diagnosed and undiagnosed diabetes: a practical review. Anaesthesia. 2019;74 Suppl 1:58-66. https://doi.org/10. 1111/anae.14510.

37. Mendez CE, Wainaina N, Walker RJ, Montagne W, Livingston A, Slawski B, Egede LE. Preoperative diabetes optimization program. Clin Diabetes. 2018;36(1):68-71. https://doi.org/10.2337/ cd17-0088.

38. American Diabetes Association (ADA). Facilitating behavior change and well-being to improve health outcomes: standards of medical care in diabetes-2021. Diabetes Care. 2021;44(1):S53-72. https://doi.org/10.2337/dc21-S005.

39. American Diabetes Association (ADA). Pharmacologic approaches to glycemic treatment: standards of medical care in 
diabetes-2021. Diabetes Care. 2021;44(1):S111-124. https://doi. org/10.2337/dc21-S009.

40. American Diabetes Association (ADA). Glycemic targets: standards of medical care in diabetes-2021. Diabetes Care. 2021;44(1):S73-84. https://doi.org/10.2337/dc21-S006.

41. Preiser JC, Provenzano B, Mongkolpun W, Halennarova K, Cnop M. Perioperative management of oral glucose-lowering drugs in the patient with type 2 diabetes. Anesthesiology. 2020;133(2):430-8.

42. Demma LJ, Carlson KT, Duggan ET, Morrow JG, Umpierrez G. Effects of basal insulin dosage on blood glucose concentration in ambulatory surgery patients with type 2 diabetes. J Clin Anesth. 2016;36:184-8.

43. Albalawi Z, Laffin M, Gramlich L, Senior P, McAlister FA. Enhanced Recovery After Surgery $\left(\right.$ ERAS $\left.^{\circledR}\right)$ in individuals with diabetes: a systematic review. World J Surg. 2017;41(8):1927-34. https://doi.org/10.1007/s00268-017-3982-y.

44. Festejo-Villamiel K, Yao C, Sioson M. Enhanced Recovery after Surgery (ERAS $®)$ outcomes in patients with prior diagnosis of diabetes. J ASEAN Fed Endocr Soc. 2019;34(1):73.

45. Kelly JL. Continuous insulin infusion: when, where, and how? Diabetes Spectr. 2014;27(3):218-23. https://doi.org/10.2337/diasp ect.27.3.218

46. Nazer LH, Chow SL, Moghissi ES. Insulin infusion protocols for critically ill patients: a highlight of difference and similarities. Endocr Pract. 2007;13(2):137-46.

47. Billiodeaux ST, Samuelson CG, Willett O, Arulkumar S, Thomas D, Hamilton CS, Jain SK, Mosieri C, Fox CJ. Intraoperative and postoperative blood glucose concentrations in diabetic surgical patients receiving lactated Ringer's versus normal saline: a retrospective review of medical records. Ochsner J. 2014;14(2):175-8.

48. Simpson AK, Levy N, Hall GM. Peri-operative i.v. fluids in diabetic patients-don't forget the salt. Anaesthesia. 2008;63(10):1043-5. https://doi.org/10.1111/j.1365-2044.2008. 05641.x.

49. Khetarpal R, Chatrath V, Kaur J, Bala A, Singh H. Impact of different intravenous fluids on blood glucose levels in nondiabetic patients undergoing elective major noncardiac surgeries. Anesth Essays Res. 2016;10(3):425-31. https://doi.org/10.4103/02591162.176411.

50. Gershkovich B, English SW, Doyle MA, Menon K, McIntyre L. Choice of crystalloid fluid in the treatment of hyperglycemic emergencies: a systematic review protocol. Syst Rev. 2019;8(1):228. https://doi.org/10.1186/s13643-019-1130-5.

51. Handelsman Y, Bloomgarden ZT, Grunberger G, Umpierrez G, Zimmerman RS, Bailey TS, ..., Zangeneh F. American Association of Clinical Endocrinologists and American College of Endocrinology - clinical practice guidelines for developing a diabetes mellitus comprehensive care plan - 2015. Endocr Pract. 2015;21 Suppl 1:1-87.https://doi.org/10.4158/EP15672.GL

52. Schnipper JL, Magee M, Larsen K, Inzucchi SE, Maynard G, Society of Hospital Medicine Glycemic Control Task Force. Society of hospital medicine glycemic control task force summary: practical recommendations for assessing the impact of glycemic control efforts. J Hosp Med. 2008;3(5 Suppl):66-75. https://doi. org/10.1002/jhm.356.

53. Umpierrez G, Rushakoff R, Seley JJ, Zhang JY, Shang T, Han J, Spanakis EK, Alexanian S, Drincic A, Kulasa K, Mendez CE, Tanton D, Wallia A, Zilbermint M, Klonoff DC. Hospital diabetes meeting 2020. J Diabetes Sci Technol. 2020;14(5):928-44. https:// doi.org/10.1177/1932296820939626.

54. Moghissi ES, Korytkowski MT, DiNardo M, Einhorn D, Hellman R, Hirsch IB, ..., American Diabetes Association. American Association of Clinical Endocrinologists and American Diabetes Association consensus statement on inpatient glycemic control. Endocr Pract. 2009;15(4):353-369.https://doi.org/10.4158/EP091 02.RA.

55. Mendez CE, Umpierrez GE. Pharmacotherapy for hyperglycemia in noncritically ill hospitalized patients. Diabetes Spectr. 2014;27(3):180-8. https://doi.org/10.2337/diaspect.27.3.180.

56. Bansal V, Mottalib A, Pawar TK, Abbasakoor N, Chuang E, Chaudhry A, Sakr M, Gabbay RA, Hamdy O. Inpatient diabetes management by specialized diabetes team versus primary service team in non-critical care units: impact on 30-day readmission rate and hospital cost. BMJ Open Diabetes Res Care. 2018;6(1):e000460. https://doi.org/10.1136/bmjdrc-2017-000460.

57. Arnold P, Scheurer D, Dake AW, Hedgpeth A, Hutto A, Colquitt C, Hermayer KL. Hospital guidelines for diabetes management and the Joint Commission-American Diabetes Association inpatient diabetes certification. Am J Med Sci. 2016;351(4):333-41. https://doi.org/10.1016/j.amjms.2015.11.024.

58. Pasquel FJ, Lansang MC, Dhatariya K, Umpierrez GE. Management of diabetes and hyperglycaemia in the hospital. Lancet Diabetes Endocrinol. 2021;9(3):174-88. https://doi.org/10.1016/ S2213-8587(20)30381-8.

59. Umpierrez GE, Reyes D, Smiley D, Hermayer K, Khan A, Olson DE, Pasquel F, Jacobs S, Newton C, Peng L, Fonseca V. Hospital discharge algorithm based on admission $\mathrm{HbA} 1 \mathrm{c}$ for the management of patients with type 2 diabetes. Diabetes Care. 2014;37(11):2934-9. https://doi.org/10.2337/dc14-0479.

60. Herbst RA, Telford OT, Hunting J, Bullock WM, Manning E, Hong BD, D'Alessio DA, Setji TL. The effects of perioperative dexamethasone on glycemic control and postoperative outcomes. Endocr Pract. 2020;26(2):218-25. https://doi.org/10.4158/ EP-2019-0252.

61. Tamez-Pérez HE, Quintanilla-Flores DL, Rodríguez-Gutiérrez R, González-González JG, Tamez-Peña AL. Steroid hyperglycemia: prevalence, early detection and therapeutic recommendations: a narrative review. World J Diabetes. 2015;6(8):1073-81. https:// doi.org/10.4239/wjd.v6.i8.1073.

62. Bajwa SJ, Haldar R. Pain management following spinal surgeries: an appraisal of the available options. J Craniovertebr Junction Spine. 2015;6(3):105-10. https://doi.org/10.4103/0974-8237. 161589.

63. Umpierrez GE, Klonoff DC. Diabetes technology update: use of insulin pumps and continuous glucose monitoring in the hospital. Diabetes Care. 2018;41(8):1579-89. https://doi.org/10.2337/ dci18-0002.

64. Partridge H, Perkins B, Mathieu S, Nicholls A, Adeniji K. Clinical recommendations in the management of the patient with type 1 diabetes on insulin pump therapy in the perioperative period: a primer for the anaesthetist. Br J Anaesth. 2016;116(1):18-26. https://doi.org/10.1093/bja/aev347.

Publisher's Note Springer Nature remains neutral with regard to jurisdictional claims in published maps and institutional affiliations. 